\title{
Psychological Burden Experienced by Polish and Slovak Nurses Working at Chemotherapy Units
}

\section{H. Kaducakova (Helena Kaducakova) 1,2, G. Debska (Grazyna Debska)1, M. Pasek (Malgorzata Pasek)1,3, L. Tomaszek (Lucyna Tomaszek)}

${ }^{1}$ Faculty of Health and Medical Science, Andrzej Frycz Modrzewski Krakow University, Krakow, PL

${ }^{2}$ Faculty of Health, Catholic University, Ruzomberok, SK

${ }^{3}$ Center for Oncology, Maria Sklodowska-Curie Memorial Institute, Krakow Division, Krakow, PL

\section{E-mail address:}

gdebska@afm.edu.pl

\section{Reprint address:}

Grazyna Debska PhD

Krakowska Akademia im. A. Frycza Modrzewskiego

Ul. Gustawa Herlinga Grudzinskiego 1

30-705 Krakow

PL

Source: Clinical Social Work and Health Intervention

Volume: 9

Issue: 1

Pages: $37-44$

Cited references: 16

\section{Reviewers:}

Victor Namulanda Wanjala

Catholic university of Eastern Africa, Nairobi, KE

Gabriela Lezcano

University of California, San Francisco, USA

\section{Key words:}

Chemotherapy. Oncology. Nurse. Workload.

\section{Publisher:}

International Society of Applied Preventive Medicine i-gap

CSWHI 2018; 9(1): 37 - 44; DOI 10.22359/cswhi_9_1_06 @ 2018 Clinical Social Work and Health Intervention

\section{Abstract:}

This study included 234 Nurses employed at chemotherapy units: 165 from Poland; 69 from Slovakia. The participants were examined with previously validated versions of Meister Questionnaire. In the assessed 
dimensions of mental load, Monotony and Unspecific Load (reaction to stress) differentiate the Nurses working at chemotherapy units in Slovakia and Poland. The working conditions of Nurses providing care to oncologic patients treated with chemotherapy both in Slovakia and Poland are connected with a burden which is the result of time pressure and excessive responsibility. Assessment of the mental load can be used to improve the organization of Nurses' work creating safe working conditions in both studied countries, taking into consideration the mobility of the workforce in the European Union.

\section{Introduction}

One of the important components of a work-related burden is mental load - defined as a subjective reaction of an employee caused by the interaction of a group of individual, technical, organizational and social factors in the work environment $(1,2)$. In the analyzed sources, the problem becomes a more frequent reason for conducting studies in different occupation groups, however not in the group of Oncology Nurses caring for patients undergoing chemotherapy $(3,4)$. Providing Nursing care in the course of chemotherapy is characterized by a certain peculiarity, which on the one hand requires interdisciplinary knowledge; diagnostic abilities; knowing what decision to make; and on the other hand becomes the source of mental load. The burden is caused by the level of involvement and the close relationship with the patients and their families, which is the result of repetitive treatments and regular hospitalizations at the ward. Consequently, this situation may lead to professional burnout and mental overload, and lowered satisfaction with life $(2,3,5)$. One of the methods of assessing mental load is subjective assessment with the use of self-description scales. However, due to a lack of a standardized tool, this method is rarely used. Moreover, there are no international studies which would allow to compare the phenomenon of mental load experienced by Nurses. Therefore, the present study was aimed at verifying whether Nurses working in a country other than

Poland are also exposed to the same mental load. For comparison we used a group of Nurses working at a chemotherapy unit in Slovakia, assuming that the study population is similar to the Polish one in terms of demographics and socio-cultural conditions, and the organization of the workplace.

\section{Methods}

The study included 234 Nurses, among them 165 from Poland and 69 from Slovakia. To provide equal sample size, 69 participants were randomly chosen from the Polish group. Therefore, eventually the data from a total of 138 Nurses (69 from each country) were included in a multivariate analysis of variance. Polish Nurses were employed at chemotherapy units for $11.77 \pm 7.65$ years on average and their mean age was 43.07 \pm 7.99 years. The group included 25 Nurses living in rural areas and 44 city- and town-dwellers. Mean age of Slovak Nurses and mean duration of their employment at chemotherapy units were similar as for Polish group (42.51 \pm 7.32 years and $10.25 \pm 6.2$ years). a total of 29 Slovak Nurses lived in rural areas and 40 in towns/cities.

The study was based on a diagnostic survey with previously validated versions of Meister Questionnaire $(1,3,6)$. Slovak Nurses were surveyed with the version approved by the Slovak Ministry of Health (7), and Polish Nurses with the version adapted by 
Debska et al. (8). Both versions were previously shown to be characterized by acceptable accuracy and internal consistency rates (Cronbach Alpha $>0.77)$ (1,3). Meister Questionnaire allows to determine three dimensions (subscales) of mental load: Overload, Monotony (monotonous load) and Unspecific Load (interpreted as unspecific response to stress). Each subscale included a number of specific items: Time Pressure; Great Responsibility; Problems and Conflicts for the Overload subscale, Low Satisfaction, Dull Work and Monotony for the Monotony subscale, and Nervousness; Oversaturation; Fatigue; Long-lasting Load for the Unspecific Load subscale. Median values for all these dimensions were compared with respective critical normalized values proposed by Zidkova $(3,6)$.

Statistical characteristics of the analyzed variables were presented as arithmetic means, standard errors of the mean, medians, standard deviations, minimum and maximum values. Normal distribution of the analyzed variables was verified with Kolmogorov-Smirnov Test. Then, mixed-design analysis of variance (ANOVA) was conducted, with nationality as a between-group factor and the scores for Meister Questionnaire as a within-group factor. The Bonferroni Correction was applied to multiple comparisons. Eta ${ }^{2}$ values were calculated to determine the effect of nationality on the analyzed parameters and intragroup differences in the scores for specific dimensions. The results of all the tests were considered statistically significant whenever their p-value were lower than 0.05 .

\section{Results}

In Slovak respondents, median values exceeded their critical values for all but two items of Meister Questionnaire: Low Satisfaction and Dull Work. In the case of Polish participants, median values for five statements exceeded their critical values. Both in Polish and Slovak group, the most problematic items turned out to be Time Pressure, Great Responsibility, Problems and Conflicts, Fatigue and Long-lasting Load (Table 1).

Table 1: Descriptive statistics for the individual items of Meister Questionnaire in Polish and Slovak Nurses.

\begin{tabular}{|c|c|c|c|c|c|c|c|}
\hline \multirow{2}{*}{ Item } & \multicolumn{3}{|l|}{ Poland } & \multicolumn{3}{|c|}{ Slovakia } & \multirow[t]{2}{*}{ Critical value } \\
\hline & Mean & Median & SD & Mean & Median & SD & \\
\hline Time Pressure & 4.04 & $4.00^{+}$ & 1.08 & 3.62 & $4.00^{+}$ & 1.02 & 3.00 \\
\hline Low Satisfaction & 2.21 & 2.00 & 1.06 & 2.38 & 2.00 & 1.02 & 2.00 \\
\hline Great Responsibility & 4.06 & $4.00^{+}$ & 1.01 & 3.16 & $4.00^{+}$ & 1.20 & 2.00 \\
\hline Dull Work & 1.74 & 1.00 & 0.96 & 2.01 & 2.00 & 0.98 & 2.00 \\
\hline Problems and Conflicts & 2.37 & $2.00^{+}$ & 1.22 & 3.24 & $4.00^{+}$ & 1.39 & 1.00 \\
\hline Monotony & 1.75 & 1.00 & 1.00 & 2.38 & $2.00^{+}$ & 1.13 & 1.00 \\
\hline Nervousness & 2.78 & 2.00 & 1.22 & 2.90 & $3.00^{+}$ & 1.25 & 2.00 \\
\hline Oversaturation & 2.07 & 2.00 & 1.15 & 3.03 & $3.00^{+}$ & 1.31 & 2.00 \\
\hline Fatigue & 3.22 & $4.00^{+}$ & 1.28 & 3.55 & $4.00^{+}$ & 1.23 & 3.00 \\
\hline Long-lasting Load & 3.70 & $4.00^{+}$ & 1.18 & 3.42 & $4.00^{+}$ & 1.24 & 3.00 \\
\hline
\end{tabular}

${ }^{1}$ According to Zidkova $[3,7] ;{ }^{+}$denotes exceeded critical limit 
Statistical analysis revealed significant differences between Polish and Slovak group in terms of the analyzed subscales.

and achieved the lowest scores on Monotony scale $\left(F_{2,135}=64.59, \mathrm{p}<0,001\right)$. The results are summarized in Table 2.

Table 2: Descriptive statistics for the subscales of Meister Questionnaire in Polish and Slovak Nurses.

\begin{tabular}{|l|l|l|l|}
\hline Subscale & Group & Mean & SD \\
\hline \multirow{2}{*}{ Overload } & Poland & 3.49 & 0.77 \\
\cline { 2 - 4 } & Slovakia & 3.33 & 0.78 \\
\hline \multirow{2}{*}{ Monotony } & Poland & 1.90 & 0.78 \\
\cline { 2 - 4 } & Slovakia & 2.26 & 0.78 \\
\hline \multirow{2}{*}{ Unspecific Load } & Poland & 2.94 & 0.97 \\
\cline { 2 - 4 } & Slovakia & 3.23 & 0.93 \\
\hline
\end{tabular}

Slovak respondents scored significantly higher than Polish ones on Monotony $\left(F_{1,136}=7.34, \mathrm{p}<0.01\right)$ and Unspecific Load scales $\left(F_{1,136}=3.09, \mathrm{p}<0.01\right)$. Further analysis documented significant subscale-to-subscale differences within both Polish and Slovak groups. Polish respondents were shown to score the highest on Overload subscale, followed by Unspecific Load and Monotony subscales $\left(F_{2,135}=117.99, \mathrm{p}<0.001\right)$. In turn, Slovak participants scored the highest on both Overload and Unspecific Load scales
In order to determine the effect of the group (Polish vs. Slovak) on the analyzed scores, respective $\mathrm{Eta}^{2}$ values were calculated. The most prominent intergroup differences were documented in the case of Monotony scale, followed by Unspecific Load and Overload subscale. Furthermore, the analysis of $\mathrm{Eta}^{2}$ values showed that the subscale-to-subscale differences in among Polish respondents were significantly more evident than among Slovak participants (Figs. 1-3).

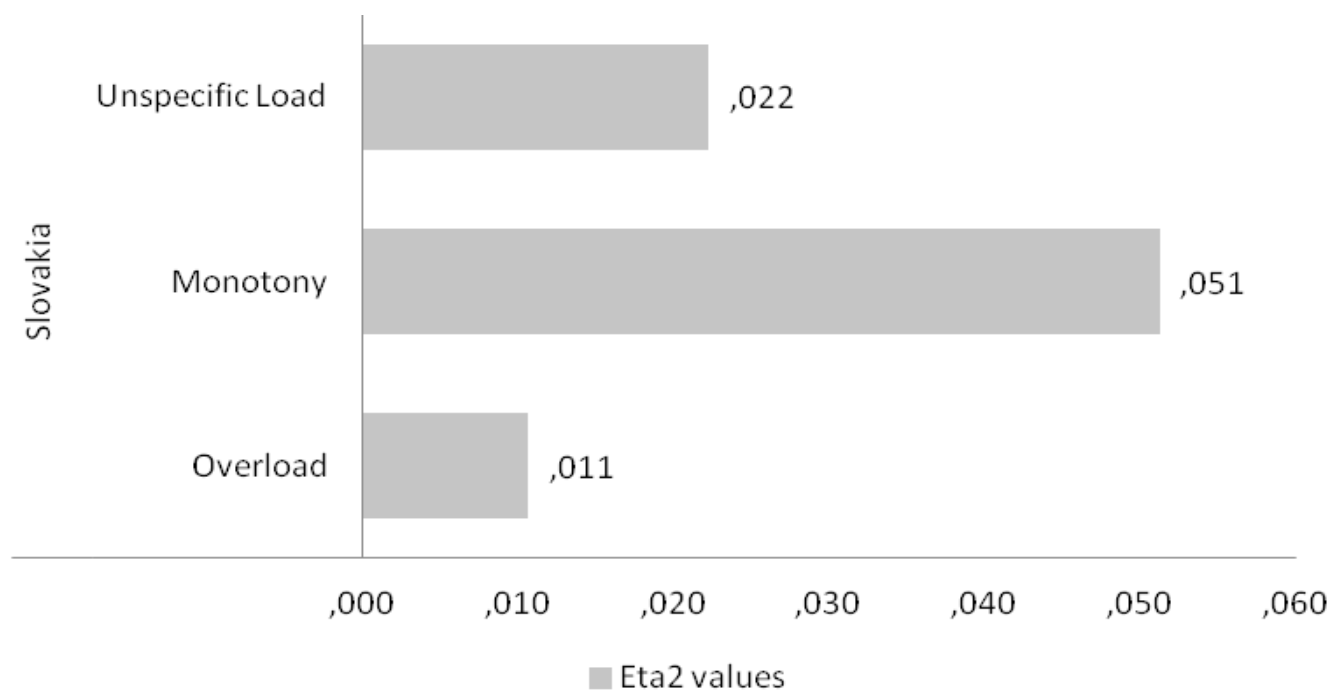

Fig. 1: Eta ${ }^{2}$ values for the subscales of Meister Questionnaire in Polish Nurses. 


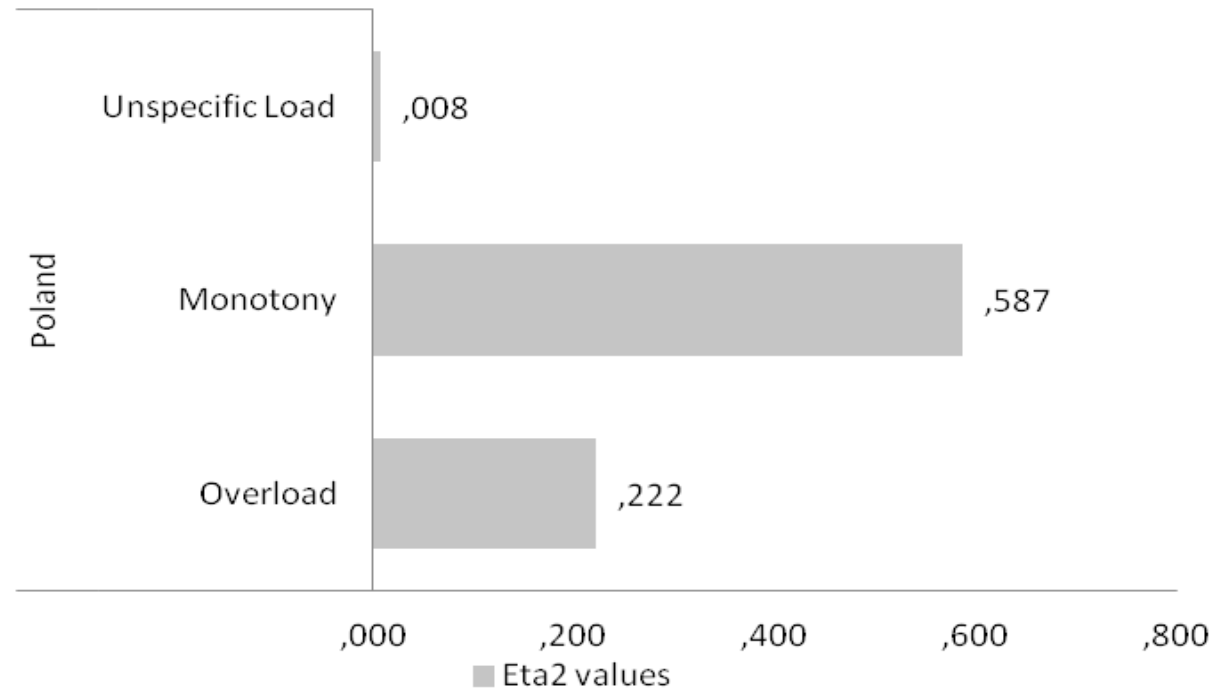

Fig. 2: Eta² values for the subscales of Meister Questionnaire in Slovak Nurses.

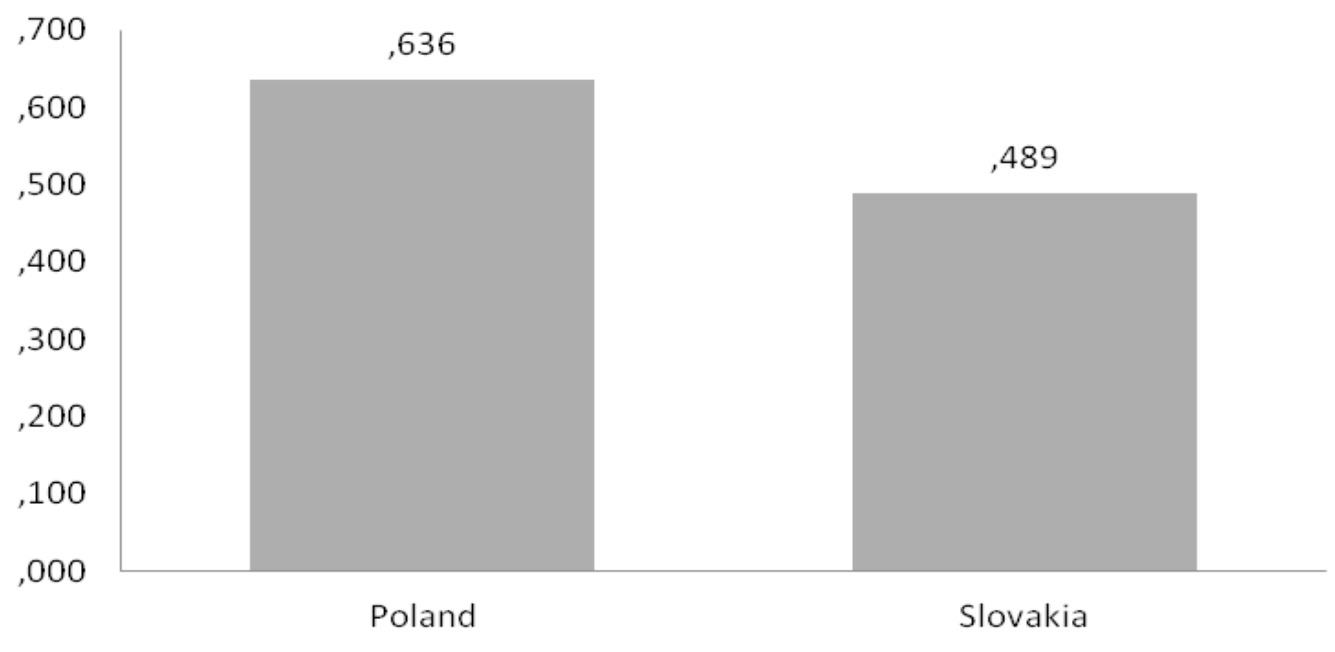

Eta2 values

Fig. 3: Comparison of cumulative Eta² values for Polish and Slovak Nurses.

\section{Discussion}

Using a standardized Questionnaire to assess current mental load allows the researcher to perform international comparisons after its prior adaptation into a relevant language. Prerequisites for such research are met by the Meister Questionnaire which was used as a screening method for assessing psychological burden in research conducted in the Czech Republic and in Slovakia $(3,6,8,9,10,11)$. In Poland, in studies by Debska et al. (12) the aforementioned research tool was used when analyzing a group of Nurses working at different units (Intensive Care, Surgical, Internal Diseases, 
Primary Care, Oncology). In all the studied groups, the second level of mental load, corresponding to overload, was found. In the same studies, the authors also documented the relationship between mental load and occupational burnout.

Zidkova (6) conducted research in the Czech Republic, using the Meister Questionnaire to assess the mental load experienced in different job positions on a large study group of 1,832 subjects including 1,300 women. None of the scores reached respective critical values. However, assessing groups of employees in the same occupation, she observed that critical values were exceeded for Overload in the case of Doctors and Nurses, and for the Unspecific Load (reaction to stress) in the group of Scrub-Nurses. In another Czech study, Mazgutova et al. (4) showed that work-related mental load in Nurses is recorded highest in terminal care units, in comparison with internal diseases or emergency wards. Moreover, in a group of 168 Oncology Nurses additional burden and stress was caused by excessive Administration as shown in a study by Zalesakova et al. (10).

Previous Polish studies did not show unambiguously that the specialization (place of work) was the factor differentiating the level of load. The results were inconclusive. In the study by Debska et al., the levels of mental load documented for Oncology Nurses did not differ from those recorded for Nurses working at other units. Another study showed that Nurses working at the Intensive Care Unit reported significantly lower levels of mental load than those working at the Surgical Ward (13). It is noteworthy that in both studies work experience was the differentiating factor for mental load, especially for the Overload and Monotony subscales - the longer the work experience, the higher the scores for the two dimensions. Zalesakova et al. also reported differences in mental load depending on work experience in Oncology Nurses. The least overburdened were the Nurses with shorter experience working at a chemotherapy unit, and the most overburdened were those working there longer (10).

An analysis of the available sources shows that the greatest work-related burden reported by Nurses employed at hospital wards was mainly associated with Time Pressure and Great Responsibility (13). In Social Care Facilities burden was caused by tiring work, rush, fatigue, too many duties (14). A study by Oginska and Zuralska (15), conducted on a group of Neurology Nurses, showed that most of the participants were overburdened with duties and experienced fatigue. Similar results were reported by Gurkova et al. (11), who documented that critical values were exceeded for Time Pressure, Great Responsibility, Fatigue and Long-lasting Load. Another study conducted among Polish Nurses working in an in-patient medical care showed that $72.6 \%$ of the respondents were exposed to stress at the workplace, despite the fact that most of them reported job-satisfaction (16).

Our present study provided similar results, since in both groups (Polish and Slovak), the greatest burden at work turned out to be associated with Time Pressure, Great Responsibility, Fatigue and Long-lasting Load; Problems and Conflicts were additionally reported in the Slovak group. The respondents scored highest in Overload and lowest in Monotony. The results for the studied groups differed significantly for Monotony and Unspecific Load, with the Slovak group scoring higher than the Polish one. With great caution we could assume that nationality may have been the differentiating factor in these subscales, seeing as, as can be surmised from the available sources and previous Czech, Slovak and Polish studies, the differentiating factor was rather place of work, age, and work experience in a given specialization. And regardless of the country 
of the study, the results were similar, which proves that Nurses have similar problems connected with the workplace. However, due to a lack of unambiguous results, it seems significant to find the factors affecting the level of work-related mental load in Nurses working in different language areas and different organization and social settings.

\section{Conclusions}

In the assessed dimensions of mental load, Monotony and Unspecific Load (reaction to stress) differentiate the Nurses working at Chemotherapy Units in Slovakia and Poland.

The working conditions of Nurses providing care to Oncologic patients treated with chemotherapy both in Slovakia and Poland are connected with burden, which is the result of time pressure and excessive responsibility.

The assessment of mental load can be used to improve the organization of a Nurse's work, creating safe working conditions in both studied countries, taking into consideration the mobility of the workforce in the European Union.

\section{References}

1. HLADKY A, ZIDKOVA Z (1999) Methods for assessing occupational psychosocial load. Karolinum Praga, 78 p.

2. LUCZAK A (2011) Standardization work of the mental work load: Psychological burden of work - new challenges for ergonomics In JULISZEWSKI T, OGINSKA H, ZLOWODZKI M Ergonomics Committee PAN , Krakow, 105-115 p.

3. ZIDKOVA Z, MARTINKOVA J, PAULOVA M, SVACINKOVA M (2001) The psychological burden of ancillary healthcare personnel. In Czech Labor Medicine 2 (Jan), 4-8.

4. KURIATA E, FELINCZAK A, GRZEBIELUCH J, SZACHNIEWICZ M (2011)
Harmful factors and workload of nurses employed in the hospital. Part II, Nursing and Public Health. Part II. In Nursing and Public Health, 2011; 1(Mar) 269-273. ISSN:1731-7398.

5. MAZGUTOVA A, ONDREJKA I, DEMETEROVA M, FETISOVOVA Z, ADAMICOVA K (2012) The psychological burden of health care workers in palliative care. In Palliative medicine and pain management, 5 Mar 95-98. ISSN:1339-419.

6. ZIDKOVA Z (2002) The application of Questionnaire in the evaluation of psychic load at work. In Czech Labor Medicine, Mar, 128-132.

7. MINISTER OF HEALTH REGULATION OF AUGUST 16, 2007 Rules of health protection against physical, mental and sensory load at work. n. 542, 3896.

8. DĘBSKA G, WILCZEK-RUZYCZKA E, FORYS Z, PASEK M (2013) Psychometric properties assessment of the Meister Questionnaire used in evaluating mental load among Nurses. In Medycyna Pracy 64(MAR) 349-358. ISSN:0465-5893.

9. HODACOVA L, SMEJKALOVA J, SKALSKA H (2007) Differences in occupational psychic load perception among workers of chosen professional groups. In Medical reports from the Medical Faculty of the Charles University in Hradec, 2007; 52 (Feb) 93-103. ISSN: 0457-4206.

10. ZALESAKOVA J, BUZGOVA R (2011) Psychological stress of Nurses taking care of cancer patients. In Labor Medicine, 20116 (3-4 2011) 113-118. ISSN:0032-6291.

11. GURKOVA E, SLAVKA M (2012) Psychological strain and depressive symptomatology between Nurses. In Nursing and midwifery, 2011 3(Jan) 326-334. ISSN: 1804-2740.

12. DEBSKA G, PASEK M, WILCZEK-RUZYCZKA E (2014a) Psychological strain and occupational burnout among Nurses of various specialties. In Hygeia Public Health, 2014; 49(Jan) 113-119. ISSN:1509-1945. 
13. DEBSKA G,PASEK M, WILCZEK-RUZYCZKA E, FORYS Z (2014b) Psychological burden experienced by Nurses in oncology units vs. Nurses employed in other medical units. In MORAVCIKOVA D, VASKO M. (eds. 2014). Family-Health-Disease 2013 Zlin: Tomas Bata University Zlin ISBN 978-80-7454-411-8. 109-119 p.

14. KADUCAKOVA H, LEHOTSKA M (2010) Factors influencing the work of Nurses in social welfare centers. In DEBSKA G, JASKIEWICZ J Interdisciplinary aspects of health sciences (eds). 2010. Krakow: AFM ISBN 978-83-7571-293-3. 176-183p.
15. OGINSKA J, ZURALSKA R (2010) Burnout syndrome in neurological Nursing. In Problemy Pielęgniarstwa 18(4 2010) 435442. ISSN:1233-9989.

16. KOWALCZUK K, ZDANSKA A, KRAJEWSKA-KULAK E, et al (2011) Stress in the work of Nurses as a risk factor for burnout. In Problemy Pielęgniarstwa 19 (Mar, 307-314. ISSN:1233-9989.

The study was financed with the use of funds from Ministry of Science and Higher Education for scientific and development research within its status activity (number of research task:

WZiNM/DS/7/2015-KON). 